\title{
Narrativas que importam: Práticas de leitura no ensino de sociologia
}

\author{
Andressa Fontana Pires' (D) \\ Fagner Carniel" (iD
}

RESUMO

Qual seria o lugar da literatura no ensino de sociologia? Em que medida a leitura de narrativas literárias poderia favorecer o aprendizado das relações de gênero e sexualidade em nossa sociedade? Por meio de experiências escolares com o conto O papel de parede amarelo, de Charlotte Perkins Gilman, este artigo problematiza o potencial pedagógico do uso da literatura no desenvolvimento de consciências e sensibilidades atentas às assimetrias, desigualdades e violências inscritas no cotidiano generificado que habitamos. Por fim, as afinidades entre literatura e teorias sociais feministas são enfatizadas enquanto possibilidades metodológicas de ensino e aprendizagem que privilegiam tanto a ressignificação do mundo social quanto a reorganização de si, no aprendizado de outras maneiras de se conceber e vivenciar a diversidade sexual.

\section{PALAVRAS-CHAVE}

educação escolar; ensino de sociologia; leitura literária; gênero e sexualidade; metodologia de ensino. 


\title{
NARRATIVES THAT MATTER: READING PRACTICES IN SOCIOLOGY TEACHING
}

\begin{abstract}
What could be the place of literature in Sociology teaching? To what extent could reading literary narratives aid the learning of gender relations and sexuality in our society? Through school experiences with Charlotte Perkins Gilman's tale The yellow wallpaper, this article argues about the pedagogical potential of the use of literature in the development of consciences and sensitivities concerned with asymmetries, inequalities and violence inscribed in the genderized daily life we live on. Finally, the affinities between literature and feminist social theories are emphasized as methodological possibilities of teaching and learning that privilege the resignification of the social world, as well the reorganization of oneself, in learning other ways of conceiving and experiencing sexual diversity.
\end{abstract}

KEYWORDS

schooling; sociology teaching; literary reading; gender and sexuality; teaching methodology.

\section{NARRATIVAS QUE IMPORTAN: PRÁCTICAS DE LECTURA EN LA ENSEÑANZA DE LA SOCIOLOGÍA}

\section{RESUMEN}

¿Cuál sería el lugar de la literatura en la enseñanza de la sociología? ¿Hasta qué punto la lectura de narraciones literarias favorecería al aprendizaje de las relaciones de género y sexualidad en nuestra sociedad? A través de experimentos escolares con el cuento El papel tapiz amarillo, de Charlotte Perkins Gilman, este artículo problematiza el potencial pedagógico del uso de la literatura en el desarrollo de conciencias y sensibilidades atentas a las asimetrías, desigualdades y violencia inscritas en la vida diaria de género que habitamos. Finalmente, las afinidades entre la literatura y las teorías sociales feministas se enfatizan como posibilidades metodológicas de enseñanza y aprendizaje que privilegian tanto la resignificación del mundo social como la reorganización de uno mismo en el aprendizaje de otras formas de concebir y experimentar la diversidad sexual.

\section{PALABRAS CLAVE}

educación escolar; enseñanza de sociologia; lectura literária; género y sexualidade; metodología de enseñanza. 


\section{INTRODUÇÃO}

A escola, as desigualdades sociais, as políticas educacionais, a carreira, as condições de ensino, a autoridade pedagógica, a atenção estudantil, a indisciplina, os risos, os celulares, os hábitos de leitura e escrita, os materiais didáticos, os conteúdos disciplinares, o currículo, as avaliações, os remédios, as doenças, as acusações, e até mesmo quem não tem nada a ver com essa história talvez se sinta confortável para demonstrar sua insatisfação. São tantas as crises de significação que assolam o imaginário docente e precarizam a vida escolar no início deste século que parece ser cada vez mais difícil encontrar momentos para indagar: Quais narrativas efetivamente importam em sala de aula?

Por meio de experiências escolares com o conto $O$ papel de parede amarelo, este artigo problematiza o potencial pedagógico do uso da literatura no ensino sociológico das relações de gênero e sexualidade. Considerado um clássico da literatura feminista, o conto foi publicado originalmente em 1892, pela escritora e ativista norte-americana Charlotte Perkins Gilman (1860-1935), e, desenrolando-se como uma narrativa em primeira pessoa, conta a história de uma mulher forçada ao confinamento por seu marido (e também médico), que pretende curá-la de uma depressão nervosa passageira. Proibida de fazer qualquer esforço físico ou mental, a protagonista fica obcecada pelos padrões do papel de parede estampado em seu quarto e acaba "enlouquecendo" de vez.

As experiências de ensino com a leitura do conto são apresentadas neste texto a partir da dupla situação de docentes e de observadoras das práticas pedagógicas propostas. Tal posição paradoxal no contexto das salas de aula exigiu que atravessássemos constantemente os papéis de educadoras e de pesquisadoras, borrando assim as fronteiras epistemológicas que tradicionalmente separam e hierarquizam ensino e pesquisa, como se fossem atividades e moralidades opostas (Carniel e Ruggi, 2015). O resultado deste estudo, portanto, está intimamente relacionado aos resultados daquelas aulas, lançando-nos em um processo de produção do conhecimento que não se estabeleceu sobre os universos escolares ou para quem frequentou a disciplina ao longo de 2019, mas que somente pôde ser desenvolvido com aquelas três turmas que se dispuseram a embarcar na aventura intelectual de experimentar a leitura coletiva enquanto uma maneira de pluralizar pontos de vista, negociar diferenças e ressignificar perspectivas.

Afinal, as experiências literárias que estabelecemos com turmas de aproximadamente 35 estudantes ${ }^{1}$ do ensino médio da região metropolitana de Curitiba remetem a conflitos, desconfortos, dúvidas, emoções, estranhamentos, indignações, inquietações, revelações e tensões que construímos juntas, ao compartilhar nossas interpretações acerca das dinâmicas do silenciamento, da invisibilização e da opressão sexual desencadeadas pela leitura do conto $O$ papel de parede amarelo.

1 Ao colocar em perspectiva o sexismo gramatical intrínseco à generalização da escrita acadêmica pelo masculino, o artigo propõe uma reviravolta narrativa ao generalizar pelo feminino — de forma geral, quando se lê "as alunas", por exemplo, subentende-se o universo total de estudantes. 
O próximo tópico aborda o potencial pedagógico da literatura no desenvolvimento de consciências e sensibilidades atentas às assimetrias, desigualdades e violências inscritas nas relações de gênero e sexualidade. Em seguida, são apresentadas algumas experiências de ensino com a intenção de demonstrar a maneira pela qual as práticas de leitura ensejam modos particulares de organização do trabalho pedagógico no ensino de sociologia. Ao final, argumentamos que a leitura coletiva favorece o compartilhamento de múltiplas interpretações a respeito da diversidade sexual que constitui o mundo social.

Desse modo, talvez se possa dizer que tais práticas de leitura compartilhada possibilitaram a transformação das aulas em algo próximo ao que Petit (2010,p. 85) já denominou "espaços transicionais"; ou seja, lugares que constroem ativamente "vínculos com o mundo interior e com o exterior, para que o íntimo e o público possam dialogar”, e, em alguma medida, reconciliar-se.

\section{PRÁTICAS DE LEITURAS E AQUILO QUE COMPARTILHAMOS NAS AULAS DE SOCIOLOGIA}

Quando lemos, os pensamentos costumam preencher nossa imaginação, fazendo conexões com vivências anteriores ou inferindo o que pode vir a acontecer. Tal processo inaugura o que Cosson e Souza (2011) já chamaram de "conversas interiores": uma forma de atribuir sentidos diversos ao que se está lendo, por meio de habilidades ou estratégias que são desenvolvidas durante o ato da leitura — tais como a ativação de conhecimentos prévios, conexões, inferências, visualizações, perguntas ao texto, sumarizações ou sínteses (Pressley, 2002). Desse modo, as constantes circulações de significados entre a história contada pela narrativa literária e as nossas próprias histórias favorecem o desenvolvimento de perspectivas e de reflexões sociológicas acerca dos fenômenos e das experiências culturais indispensáveis à escolarização básica.

Portanto, ao trazer textos literários para a sala de aula como gérmens de experiências compartilhadas, apostamos no processo de (re)criação de intersubjetividades. Trata-se, em outros termos, de conceber a literatura como um recurso didático capaz de promover reorganização de si e do mundo que nos cerca, na medida em que a ficção feita palavra na narrativa e a palavra feita matéria no papel são processos formativos tanto da língua quanto das leitoras. De acordo com Cosson (2018, p. 16), "uma e outra permitem que se diga o que não sabemos dizer e nos dizem de maneira mais precisa o que queremos dizer ao mundo e a nós mesmas”.

Suscitadas pela leitura coletiva, as múltiplas vozes que assumem a narrativa acabam fazendo com que as turmas experimentem a escuta (e a presença) de suas colegas. Assim, os atos de ouvir e ser ouvida parecem favorecer certa conexão entre pessoas diferentes, por meio de uma imersão sensorial que convoca o próprio corpo à experiência — ou, ainda, como já escreveu Castarède (2000, p. 202), "a voz viva é o contrário da letra morta e da linguagem estereotipada". Como uma oferta de espaço, o texto ficcional lido em conjunto não predispõe de um manual fixo, pois, como a própria ideia de experiência literária sugere, as trajetórias podem se desenrolar cada qual por caminhos diversos. O que nos interessa aqui é a atividade 
social de negociação de significados, como prática polissêmica, coletiva, multívoca, polifônica, que a experiência da leitura ativa (Seoane, 2004).

A partir dessas considerações, podemos compreender a leitura enquanto um tipo de prática que atravessa nossa existência das mais diversas formas, dependendo sempre do modo como nos relacionamos e significamos os textos. Tal constatação nos parece apontar para a ideia de letramento como uma categoria produtiva para pensarmos as inúmeras relações potenciais entre pessoas e textos no campo educacional; ou seja, uma perspectiva que salienta a potência do texto escrito a partir dos conhecimentos que a ele são articulados e perpetuados. Dessa forma, como sugerem Cosson e Souza (2011, p. 102), a prática do letramento pode contribuir para que possamos nos apropriar dos sentidos que comunicamos "pela escrita, pelos modos como usamos a escrita para nos comunicar e nos relacionar com as outras pessoas, pela maneira como a escrita é usada para dizer e dar forma ao mundo".

Para que a literatura cumpra seu papel humanizador e possa se articular como uma possibilidade de compreensão daquilo que nos cerca, bem como de nós mesmas, ela deve ser encarada como uma experiência em si, pois, mais do que um conhecimento a ser reelaborado, as narrativas potencializam o diálogo entre o eu e a outra. Desse modo, alargam os limites de tempo e espaço de nossas vivências, sem que, para isso, tenhamos que deixar de lado nossas trajetórias anteriores. Lidas por meio das práticas de letramento, as histórias literárias evidenciam todo o seu potencial reflexivo na medida em que se torna possível potencializar suas narrativas, sem que transformemos o texto em simulacro de si mesmo (Cosson, 2018). Portanto, é justamente com a leitura coletiva em sala de aula que nos deparamos com a oferta de um trânsito de sentidos evocados por uma multiplicidade de vozes - compartilhamento que, por si só, detém o potencial de tornar a experiência significativa e proveitosa ao ensino de sociologia.

Nesse sentido, torna-se possível compreender que práticas sociais envoltas em narrativas são instâncias da comunicação humana, que envolvem habilidades e conhecimentos permeados por relações de poder relativas a seus usos sociais, em meio a realidades específicas. Trata-se de um processo que se apresenta dialógico na medida em que institui inúmeras relações de sentido simultaneamente construídas a partir da interação entre "leitora, autora e texto, bem como entre alunas, textos e professoras" (Macedo, 2019, p. 42, tradução nossa). Resta-nos, agora, a pergunta: Como processos de significação de conteúdos sociológicos, mais especificamente orientados ao gênero e à sexualidade, podem se articular à leitura literária em um contexto no qual ambas as áreas de conhecimento (sociologia e literatura) vislumbram inúmeros percalços e questionamentos quanto a sua relevância educacional? E mais, como as narrativas literárias se articulam com as narrativas juvenis em meio a esse contexto?

No próximo tópico, relatamos três experiências pedagógicas, a partir das considerações aqui elencadas, que nos pareceram representativas do trabalho realizado com as turmas do segundo ano do ensino médio com quem convivemos em 2019. Por meio desses relatos, pretendemos situar algumas das pistas que as práticas de leitura coletiva nos ofereceram para refletir sobre os possíveis diálogos entre narrativas, salientando tanto as possibilidades do uso de textos literários em uma pedagogia feminista, quanto a latência dos debates desenrolados pelo trânsito das significações compartilhadas. 


\section{O PAPEL DE PAREDE AMARELO E OUTRAS VOZES EM SALA DE AULA}

Em uma noite fria de quinta-feira, foi sugerida a leitura do conto $O$ papel de parede amarelo para turmas de segundo ano com as quais trabalhamos ao longo do ano letivo de 2019. Eram turmas com um perfil discente muito semelhante, predominantemente formadas por jovens estudantes de escolas públicas da Região Metropolitana de Curitiba, inseridas em uma faixa etária de 15 a 19 anos e majoritariamente trabalhadoras. Cada qual, no entanto, era portadora de especificidades que tornaram múltiplas as dinâmicas da leitura compartilhada. Como recorrência, apontamos para o fato de que, em todos os grupos, a proposta sugerida foi, em um primeiro momento, recebida com desconfiança e curiosidade. Ao distribuir o excerto impresso para cada uma das estudantes, observamos dinâmicas variadas com o material recebido. Muitas contavam prontamente a quantidade de páginas. Outras liam e repetiam baixinho o nome da autora e da obra. Outras logo perdiam o foco em detrimento das telas iluminadas de seus celulares. Em algumas salas, antes mesmo de terminar a entrega, já se notava iniciativas para se iniciar a leitura. Às vezes, o silêncio imperava e a espera por uma voz solícita tomava alguns minutos.

Vencidas as primeiras dificuldades, apaziguadas certas inseguranças e mesmo sanadas algumas curiosidades, as leituras começavam geralmente muitos minutos após o início do tempo das aulas. Uma dessas experiências ocorreu com o segundo ano, e D. Júlia ${ }^{2}$ foi a primeira a se prontificar, sendo a grande protagonista dos "erros de percurso" interpelados pela turma. Paula e Rebeca, amigas próximas de Júlia, também passaram a se revezar na leitura, ao passo em que a turma sancionou a prática de interrupções por meio das gargalhadas. José, contudo, aparentava ser o mais "incomodado" com os "erros" de leitura, perdendo a sequência dos acontecimentos narrativos, pois, volta e meia, cochichava aos amigos piadas ou ria escancaradamente das "gafes", especialmente de Júlia.

Em meio a conversas paralelas, a celulares luminosos e a fones de ouvidos estridentes, a leitura tomava corpo. Por vezes, o texto vencia as distrações, por vezes, perdia o foco, entretanto, a turma como um todo parecia acompanhar, a sua maneira, a história lida. Certa feita, ao indagar sobre o significado da palavra "diligentemente", Júlia protagonizou um trava-língua que novamente foi ponto alto para as risadas. Quando indicada a definição da palavra como algo relacionado à ideia do cuidado, zelo e atenção, a garota voltou os olhos ao papel, sendo, contudo, novamente interrompida. José caçoou da colega ao afirmar que, em seu processo de leitura, Júlia não estava sendo diligente. Em seguida, ao ser indagado se conseguiria ser diligente, se poderia demonstrar essa qualidade lendo um pouco para a turma, José remexeu-se na carteira, demonstrando certo incômodo, e se dispôs, enfim, à leitura.

Com os olhos fixos no texto, o garoto iniciou a narrativa com a pronúncia baixa, e, aos poucos, foi elevando a voz; nesse momento, toda a turma parecia estar à espera de qualquer deslize. Não tardou e José cometeu sua primeira "falha" - gaguejou ao pronunciar "flagrada", e, de prontidão, as risadas tomaram vez. Retomando a fala,

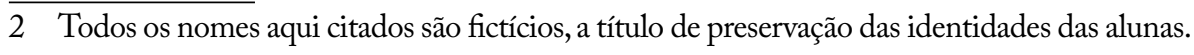


contudo, José titubeou novamente e a "zoação" recomeçou. Prontamente, o garoto interrompeu a leitura, olhou para as colegas e pronunciou ofensas, suscitando ainda mais o riso de todas. Após o acontecido, retomamos a palavra, e a leitura terminou em meio a uma atmosfera de aparente concentração - deste modo, vale ressaltar que a voz da professora parecia acalmá-las, talvez por ser a voz "habitual", à qual era permitida até mesmo entonações e encenações que pareciam divertir a turma.

Ao fim da narrativa, o silêncio novamente tomou conta. Ao serem indagadas sobre ao conto, a maior parte da turma permaneceu quieta, a não ser pela rápida contribuição de Ana sobre uma possível doença da protagonista. Na sequência, Paola também compartilhou sua interpretação, repetindo de diversas formas que a moça do texto estava muito triste, que deveria sofrer muito e que o sofrimento intenso pode vir a deixar as pessoas "malucas". Ainda segundo a garota, as grades não deixavam a personagem escapar de sua situação, e, portanto, estariam representando algo além. Algo como a opressão do marido, pois este não permitia que a moça escrevesse, nem se engajasse em outras atividades - metáfora para o machismo, como a aluna afirmou posteriormente. Muitas alunas concordaram com as considerações da colega, e, então, o sinal soou. Recolhendo os textos, Júlia disse, sorrindo, que havia gostado muito da experiência, e, ainda, sugeriu a possibilidade de se repetir tal atividade futuramente.

No que concerne à segunda prática de leitura coletiva, esta foi vivenciada na turma A, sendo recebida com certo descaso por grande parte do grupo — os textos em mãos logo foram parar nas carteiras ou até mesmo derrubados "acidentalmente" pelo chão. Após as devidas apresentações da narrativa, Maria se prontificou à leitura. Durante a dinâmica, havia um jogo de futebol acontecendo, fato este que volta e meia era relembrado, à medida que, a cada lance mais emocionante, corpos se contorciam nas cadeiras, bem como pronunciamentos curtos mantinham o restante da sala informada; frases soltas que eram ditas quase que em sincronia com a leitura, reproduzidas de forma rápida e direta, aparentemente sem o intuito de desviar a atenção, mas manter as informações do jogo atualizadas enquanto também se lia o texto proposto. Mateus, o principal informante, compartilhava dos acontecimentos a partir de um fone encaixado apenas no ouvido esquerdo, enquanto, teoricamente, "utilizava" o outro ouvido para acompanhar a leitura coletiva, de modo que não soltava o texto ou desviava os olhos da narrativa.

Após alguns parágrafos, Maria se cansou da leitura e disse que já havia lido demais. O silêncio tomou a sala, e, após alguns segundos, Douglas sugeriu que sua amiga Natália protagonizasse o momento da fala, sugestão que foi prontamente replicada por colegas a sua volta, com o intuito, aparentemente, de "zoação". Performatizando certo incômodo, a garota olhou para os colegas (todos meninos) e os chamou de "machistas", acusação que, aliás, já havia sido direcionada ao grupo em outras ocasiões. Minutos após a retomada da narrativa, uma gravação de celular chamou a atenção de todas as presentes: "parece que algo deu errado", frase pronta e automática que indicou alguma interrupção de comando. Como era de se esperar, o riso rolou solto, e, na tentativa de acalmá-las, retomamos o protagonismo da leitura por alguns minutos - novamente, a voz da professora pareceu acalmar a sala, ou, ainda, retomar a lógica da atenção que havia sido colocada em suspenso pelas gargalhadas insistentes. 
Em meio a uma leitura atenta, apontamentos sobre o texto foram pouco a pouco pronunciados, sem, contudo, desviar a dinâmica da narrativa. Até mesmo o outro gol anunciado foi abafado pelo interesse no texto, em meio a um "shhh" coletivo, entoado enquanto se lia que "finalmente descobri uma coisa...". O que a moça havia descoberto nesse tal de papel de parede amarelo? $\mathrm{O}$ suspense venceu o interesse pela partida de futebol, fazendo com que a curiosidade pairasse pela sala e suscitando, inclusive, o interesse de Léo, aluno surdo, que, acompanhando a narrativa por meio da tradução feita por seu intérprete Cláudio ${ }^{3}$, esboçava (com o restante da turma) ansiedade pelo desfecho do conto. Quando, finalmente, a descoberta foi revelada, o espanto tomou a sala. Nesse momento, Léo fez questão de compartilhar sua interpretação, e, por meio da tradução de seu intérprete, disse que a mulher rastejante da história se assemelhava à $\mathrm{Momo}^{4}$, figura assustadora que há alguns anos ficou conhecida por suas aparições em vídeos da internet, e, ainda, pelos supostos comandos "perigosos" que dava às crianças.

Localizada na parte frontal da sala, a discussão foi pouco a pouco se alargando, alcançando agora o "fundão", que, até então, ouvia em silêncio. Foi nesse momento que Patrícia, menina que até então nunca havia participado "ativamente" de uma de nossas aulas, tomou a voz. Como se em meio a uma epifania, afirmou que a moça do conto estava doente e alucinando em um sanatório, pois, supostamente, havia perdido um filho - seguindo a linha de raciocínio da garota, esse acontecimento teria deixado a personagem extremamente transtornada, ao ponto de ter perdido a razão, se tornando, em suas palavras, "louca". Douglas, pensativo durante as reflexões de Patrícia, compartilhou sua interpretação, apontando que a personagem do conto deveria estar sob o efeito de "drogas pesadas", portanto enfrentando algum tipo de alucinação, situação que muito possivelmente a estaria deixando "louca".

No mesmo instante, Cláudio, intérprete de Libras, teceu comentários afirmando que as visões da personagem deveriam ser fruto de um "espelho", conclusão que embasou citando a cena na qual a moça busca, por entre as janelas, outras mulheres rastejantes no bosque e na estrada, contudo, só consegue olhar uma de cada vez através do vidro, embora se vire o mais rápido possível. Natália, nesse momento, concorda com a teoria, reforçando a ideia de que a história do conto nada tem a ver com a perda de um filho ou uso de drogas, mas que tudo acontece porque a protagonista do conto vê uma mulher rastejante por entre as janelas, e isso nada mais é que o seu próprio reflexo - percebendo isso, a moça do texto teria ficado "fora de si" por se dar conta de sua própria condição "rastejante", ideia que finaliza sua reflexão, e, prontamente, é acompanhada por uma comemoração, como se Natália tivesse, de fato, desvendado

3 Com o reconhecimento dos direitos linguísticos da população de pessoas surdas usuárias da Língua Brasileira de Sinais (Carniel, 2018) e a implementação do decreto federal n. 6.571 de 2008, que prevê que todas as escolas devem matricular a totalidade de discentes com necessidades educacionais especiais nas classes comuns do ensino regular (Américo, Carniel e Takahashi, 2014), a presença de intérpretes e estudantes surdos em sala de aula foi rotinizada nos sistemas públicos de ensino do país.

4 Momo é o apelido dado a uma personagem virtual inspirada na escultura Mother bird, de Keisuke Âiso. 
o "quebra-cabeças". Douglas, no mesmo instante, interpela a garota e a repreende, afirmando que quem, na realidade, havia "desvendado o quebra-cabeças" fora ele não pelo reflexo, mas pelas "drogas". Com isso, a menina tentou argumentar seu ponto de vista; no entanto, foi prontamente silenciada pelo colega, que passou a repetir insistentemente a ideia de que quem de fato havia "interpretado corretamente" teria sido ele. Após o ocorrido, Douglas ainda buscou aprovação, indagando se havíamos compreendido sua teoria; na ânsia de uma resposta afirmativa, contudo, frustrou-se quando foi "alertado" de que essa era uma dentre tantas possíveis.

Cláudio, nesse momento, tomou a palavra e modificou o rumo da conversa. Chamou atenção para o que Léo havia dito: o garoto acreditava que a história lida era, sem dúvida, uma história de terror. Relatou ainda que Léo havia narrado sua interpretação como se fosse uma "cena de filme", e, sendo assim, chamou a atenção de todas em volta para que o garoto pudesse "encenar" novamente. Com dois dedos voltados para baixo, Léo representava um ser qualquer em movimento, o qual passou a "trilhar caminhos" em um deslocamento contínuo. Contudo, após alguns segundos, o garoto desfez os dedos como indício de um sumiço, movimento este que repetiu inúmeras vezes, enquanto suas expressões remetiam ao suspense, ao espanto, e, por fim, ao medo.

$\mathrm{Na}$ experiência literária desenrolada na turma $\mathrm{C}$, a narrativa se iniciou guiada pela voz de Lúcia. Tendo em vista as inúmeras mãos que se levantaram dispostas à leitura, houve a sugestão de que, assim que a vontade de se colocar viesse, tomassem a palavra, mesmo que a frase, o parágrafo ou a ideia não tivessem sido concluídas pela leitora da vez. Por meio desse acordo, vivenciamos uma dinâmica muito distinta das até então articuladas. As vozes foram múltiplas, revezando-se de maneira aleatória, e, muitas vezes, concorrentes na disputa para encabeçar o protagonismo da fala. Houve, contudo, o grande monopólio narrativo por parte de Lúcia e de sua colega próxima, Flávia. As duas haviam estabelecido, como que em um acordo implícito, a dinâmica da leitura do texto, alternando-se de maneira rápida e sincronizada, deixando muitas alunas frustradas por não conseguirem ocupar o espaço da fala.

O jogo começou a ser compartilhado pelo restante da sala como se fosse uma competição, com o intuito de se conquistar o monopólio, e, portanto, o protagonismo da locução. Nesse momento, garotos sentados ao fundo da sala, que, até então, não estavam compartilhando da leitura, foram cativados pela lógica estabelecida e procuraram, cada qual, ansiosamente, pela linha recém lida. Neste momento, Wesley ficou por muito tempo olhando e rindo para o papel em suas mãos, ensaiando projetar a voz, mas logo desistindo, pelo fato de Lúcia e Flávia (que estavam à frente e não haviam percebido a movimentação) resistirem em sua sincronia. Contudo, um timbre inesperado tomou espaço - Marcos quebrou a hegemonia de maneira tímida e gaguejante, porém, ganhando força aos poucos. Ficou perceptível o nervosismo do garoto; entretanto, a sala aceitou seu momento, e, inclusive, muitas o auxiliaram quando este se confundiu com a pronúncia de uma ou outra sílaba.

O texto passou para a página seguinte, e Wesley ganhou coragem, entrando para o quadro das vozes a serem ouvidas. Seus amigos, por sua vez, pareceram ficar ainda mais agitados, à medida que acompanhavam a leitura e lançavam olhares maliciosos ao colega que, mesmo projetando a voz, manteve a narrativa em tom baixo, forçando a sala a fazer ainda mais silêncio. Tales, amigo de Wesley, pareceu gostar da 
brincadeira, e também se propôs ao protagonismo - a sincronia sugerida por Flávia e Lúcia foi restabelecida, em tom cômico, agora pelos amigos. Como que portadora de uma piada subtendida, a turma toda manteve o olho no papel, e ria esporadicamente da situação encenada pelos meninos. Nesse momento, a frase "ele penetra" foi pronunciada por um dos leitores em alto e bom tom, contando ainda com uma entonação diferenciada, o que causou ainda mais risadas espalhadas pela sala.

Ao fim do texto, todas se entreolharam na ânsia de alguma explicação, contudo, mantiveram-se em silêncio e sorrindo. Após alguns longos segundos, Clóvis, garoto que, até o presente momento, estava acompanhando a leitura de forma silenciosa, voltou-se à turma como se portador da resolução de um enigma, e explicou que o papel estava tampando um buraco na parede, e, por isso, a personagem do conto não conseguia arrancá-lo. Ainda perguntou, de forma retórica, se a turma havia percebido que para "resolver o problema" seria suficiente apenas se livrar do papel, o retirando da parede; entretanto, a moça não o fazia justamente pelo fato de o papel ter a função indicada. Entretanto, ao aderir à interpretação do colega, Pedro sugeriu que, independentemente da função originária do papel, se este estava de fato fazendo mal à moça, a única alternativa seria, obviamente, arrancá-lo. Em meio a essa discussão, Marcos levantou a voz e afirmou que um possível motivo seria o fato de o papel de parede estar representando uma "dor", e, ainda, uma dor relacionada ao marido da personagem, raciocínio que o levou a considerar o machismo como gérmen da referida situação. Nesse momento, toda a turma fez silêncio, talvez digerindo a ideia.

Após alguns segundos, Tom, que estava, até então, todo desajeitado em sua cadeira, com o papel sendo amassado em uma das mãos, deu um pulo sentado, arrumou a postura e pronunciou a conclusão de que as mulheres rastejantes representariam na história a falsa liberdade das mulheres na sociedade de hoje, ao passo em que se "arrastam", mas não saem do lugar. Condição que dá uma impressão de movimento, mas um movimento lento - além de demorado e dolorido, como completou Flávia. Dessa forma, a turma deu o texto por finalizado, aceitando que, de fato, o papel "camuflava" o buraco do machismo, e que o rastejar representava a agonia das mulheres presas a esse "padrão social".

As conversas paralelas voltam à tona. Faltavam apenas 5 minutos para o soar do sinal. Nesse momento, demo-nos conta do quanto havíamos conversado conjuntamente, e ficamos surpresas como fato da atenção ter permanecido até pouquíssimo tempo antes do término da aula, pois, geralmente, logo nos últimos 15 minutos, a paciência costuma se acabar, vestem-se os casacos e as mochilas começam a ser organizadas para o momento da partida. Foi solicitado, nesse momento, que organizassem as carteiras e catassem os papéis de bala jogados pelo chão, pedido que foi acompanhado por um leve alvoroço na sala. Em meio às colegas se movimentando de um lado para o outro, Pedro pareceu tomar coragem para expor algo que parecia o estar deixando confuso. Ele entoou em alto e bom som a dúvida que lhe tomava a cabeça, indagando, assim, o motivo pelo qual, em meio a reflexões desse tipo, apenas

5 Fazendo referência ao cheiro do papel de parede que se fixava nos cabelos da personagem. 
se falam de mulheres - "por que não é um homem refletindo sobre as coisas que o prendem...?". Contudo, antes mesmo do garoto terminar a frase, Wesley, que estava do outro lado da sala, deu um grito em resposta: "Oh, Pedrão, quer dizer que você se sente preso?", e soltou uma gargalhada, alternando o olhar entre Pedro e suas outras colegas. O sinal, enfim, bateu, e a turma saiu a toda velocidade - contudo, ouviu-se muito mais "boa noite, prof.!" do que o habitual.

\section{GÊNERO E SEXUALIDADE: NARRATIVAS QUE IMPORTAM NO ENSINO DE SOCIOLOGIA}

O conto $O$ papel de parede amarelo foi selecionado para compor as sequências didáticas que apresentamos no tópico anterior justamente por ser um clássico da literatura feminista. Escrito no século XIX, o texto articula reflexões a respeito do silenciamento intelectual de mulheres em um período no qual a própria possibilidade da autoria desafiava o imaginário norte-americano hegemônico. Sem dúvida, ao colocar em perspectiva os espaços ocupados, bem como as contradições enfrentadas por mulheres letradas na formulação de uma opinião pública, sua leitura enseja a problematização de relações de poder que, no passado como no presente, operam enquanto instrumentos de perpetuação da dominação masculina. Todavia, a exemplo do que as práticas de leitura que vivenciamos na escola demonstram, o conto de Gilman também detém o potencial de ativar muitos outros debates.

Essas maneiras coletivas de produzir variadas interpretações, ao mesmo tempo particulares e comuns, por meio da leitura da obra, constituem um dos elementos primordiais do que estamos denominando letramento literário na escola: um processo pelo qual se instiga a contextualização e a significação tanto da narrativa em si, quanto dos repertórios estudantis que tais conteúdos podem suscitar. Dessa forma, recuperar narrativas de escritoras em sala de aula nos parece ser uma maneira de romper com a invisibilidade histórica que tem constrangido gerações de estudantes a desenvolver suas perspectivas sobre o mundo social, sem que consigam construir o que Nísia Floresta (2016), há quase dois séculos, chamou de um conhecimento verdadeiro sobre si mesmas.

Quem não está familiarizada com o cotidiano escolar, ou nutre representações exclusivamente professorais dos processos de ensino-aprendizagem, talvez possa se sentir desconfortável com as experiências relatadas neste texto. Contudo, procuramos deslocar nosso foco argumentativo em direção às recepções estudantis da obra que conseguimos registrar em meio à condução das aulas. O resultado foi a descoberta de múltiplos e complexos processos de significação suscitados pela leitura coletiva. Nem sempre soubemos como reagir adequadamente às manifestações que nos foram oferecidas em sala de aula; mesmo assim, procuramos organizar aquelas experiências pedagógicas a partir da tentativa de assegurar a participação de todas as pessoas em sala de aula, para que, em conjunto, pudéssemos pluralizar as interpretações e negociar significados.

Nesses momentos de intensas especulações acerca dos possíveis sentidos implicados na narrativa de Gilman, certas aproximações foram estabelecidas entre os 
assuntos suscitados pelo texto literário, e os repertórios estudantis foram mobilizados nas discussões. Por meio das mais diversas reações estudantis, deparamo-nos com dinâmicas circulares, que, aos moldes de uma comunidade pedagógica (Hooks, 2013) tiveram como principal intuito romper com uma didática unilateral historicamente pautada pela fragmentação e redução das habilidades reflexivas estudantis. Trata-se da quebra de um modelo pedagógico engessado, que, por si só, se apresentou como um dos principais objetivos de nossa didática contra-hegemônica, ao passo em que, por meio da experiência literária, orientamo-nos ao diálogo e ao protagonismo estudantil como forma de significação de conteúdos sociológicos tão relevantes às realidades dessas jovens. Destarte, o "privilégio epistêmico"(Grosfoguel, 2016, p. 25) reproduzido pela figura professoral encontrou possibilidades de ser repensando, ao passo em que vozes outras foram reivindicadas - vozes que por muito tempo foram silenciadas em meio às estruturas e instituições que reproduzem violências epistêmicas "frente aos projetos imperiais/coloniais/patriarcais que regem o sistema-mundo".

Ao colocar as ideias em movimento, as múltiplas experiências pedagógicas vivenciadas pelas leituras compartilhadas apontaram para a simbolização de experiências pessoais que, aparentemente, não tinham nenhuma relação com a história lida. Por meio de uma "verbalização dos sentimentos" (Petit, 2010), uma das grandes potências das experiências elencadas foi justamente a possibilidade encontrada pelas estudantes de acessar, a partir de diferentes perspectivas, territórios interiores talvez nunca antes explorados. Isso constitui ponto alto para a própria contextualização sociológica, considerando que a disciplina, evidentemente, se utilizou de processos reflexivos próximos aos universos (re)criados pelas alunas, que, por muitas vezes, só tiveram um contato "seco" com a disciplina, ou seja, puramente teórico e objetivo, orientado para um mero repasse de informações, tal como conceitos, acontecimentos e datas.

As práticas de leitura vivenciadas em grupo favoreceram, em última instância, o compartilhamento de interpretações, criando um contexto de diálogo reflexivo (Lajolo, 2009) entre narrativas, interpretações e conceitos sociológicos. As alunas, ao se questionarem sobre as alucinações da moça confinada em uma casa de campo, história que, em um primeiro momento, parecia algo tão longínquo e alheio às suas realidades, pouco a pouco atribuíram contornos inteligíveis à narrativa, a partir de um exercício de alteridade encabeçado por cada leitora em questão. Deparamo-nos, portanto, com processos de significação da história lida que não só ofereceram temas relevantes às conversas articuladas em cada experiência, como também sugeriram novas formas de explorar esses temas ao se estimular uma "audácia imaginativa" (Hirschman, 2011).

Desse modo, presenciamos nas salas de aula, em reação à leitura do conto, a manifestação de diferentes experiências, perspectivas e sociabilidades juvenis, que são articuladas no cotidiano escolar nas práticas de "zoação". Tais práticas, em analogia ao que já observou Pereira (2017) a respeito das juventudes estudantis na periferia de São Paulo, confrontam as formas institucionais da disciplina escolar por meio

6 Em outras palavras, um espaço no qual a capacidade de gerar entusiasmo está ligada ao interesse que se tem uma pela outra, por ouvir a voz uma da outra, por reconhecer a presença de todas. 
de linguagens e manifestações próprias aos grupos juvenis, a fim de desestabilizar o controle e a vigilância a que tradicionalmente estão sujeitos "dentro" e "fora" das salas de aula. Ao "zoar" suas colegas, o conto de Gilman e os próprios encaminhamentos que procuramos propor para a prática da leitura, as alunas estavam "zoando" a organização escolar e estabelecendo no interior da turma tensões entre seriedade e ludicidade. Mas essas maneiras de contestar a ordem estabelecida também estão ancoradas em repertórios culturais de sua geração, que são estruturados por lógicas de discriminação, generificação, racialização e subalternização das relações sociais e essa parece ser a principal marca das ambiguidades inscritas nas "zoeiras" juvenis ${ }^{7}$.

Por isso mesmo, os repertórios mobilizados em meio às práticas de leitura coletiva propostas em nossa experiência revelam tanto a saturação da disciplina escolar quanto a sua reestruturação em redes de poder que reforçam preconceitos, estereótipos e desigualdades sociais. Uma cena que nos pareceu exemplar nesse sentido ocorreu quando Natália foi constantemente colocada à prova por Douglas, ao ser acusada de "plágio" de uma ideia que de fato era sua, ou, ainda, quando silenciada no momento em que buscava dar uma "explicação" sobre o ocorrido - algo que prontamente foi apontado pela jovem como mais uma dentre tantas práticas de opressão que identificava no grupo dos colegas. Mas esse não foi o único momento em que a atividade explicitou a generificação das disputas. Outro episódio que nos pareceu significativo aconteceu com Pedro. No momento em que indagou pelas expressões múltiplas da masculinidade, foi prontamente zoado por Wesley, como se ele, enquanto homem, não pudesse se sentir oprimido ou empático diante de vivências que escapam dos padrões sexuais hegemônicos. Houve, ainda, a extrema dificuldade enfrentada por Júlia ao ser constantemente exposta por seu colega José por seus "erros de percurso", que, mesmo cometidos posteriormente pelo garoto, pareceram ser mais "escandalosos" quando protagonizados pela colega.

Ao observar aqueles conflitos, disputas e contradições no modo como pensamos e falamos sobre a sexualidade, não estamos sugerindo que a leitura de $O$ papel de parede amarelo contenha em si mesma as chaves para abrir a caixa de pandora das desigualdades e exorcizar todos os demônios de uma geração. No lugar disso, o que aquelas experiências nos apresentaram foram alguns caminhos potenciais que os usos pedagógicos de textos literários podem assumir no ensino, ao oferecer momentos de abertura, de experimentação, de exposição e de construção comum de sentidos e significados. Caminhos que nos levaram ao abandono de qualquer modelo que idealize uma única direção para as aulas ou qualquer metodologia de ensino rigidamente construída sem a presença das turmas, mas que, em contrapartida, permitem a valorização do trabalho coletivo, da cooperação na construção de leituras possíveis e o compartilhamento das experiências e das referências culturais de cada aluna.

Afinal, seja pelo reconhecimento dos processos de patologização das relações de gênero, como observaram Patrícia e Marcos, pela subordinação das mulheres

7 Um exemplo dramático dessas ambiguidades que envolvem a "zoeira" na sociabilidade cotidiana foi a campanha de difamação da então presidenta Dilma Rousseff, com artefatos culturais que geram, simultaneamente, solidariedades e hostilidades, memes misóginos que desencadeiam risos e favorecem "a raiva reacionária e a manutenção das relações estruturais de poder” (Carniel, Ruggi e Ruggi, 2018, p. 526). 
em uma sociedade dominada por lógicas masculinas, como apontam Natália, Tom e Flávia, ou mesmo pela naturalização de violências simbólicas perpetradas por aqueles que gozam de seus privilégios sociais, como sugerida por Clóvis e Marcos, presenciamos a construção de um tipo de pedagogia feminista que exige o protagonismo e o reconhecimento de repertórios estudantis.

Por conseguinte, o debate de gênero e sexualidade a partir das narrativas escritas por mulheres parece favorecer o alargamento das práticas escolares para além da hegemonia de um horizonte epistêmico masculinizante e heteronormativo, bem como a articulação de reflexões sociológicas acerca dessas relações históricas de poder. As afinidades entre literatura e teorias sociais feministas são percebidas aqui enquanto potenciais metodológicos, que privilegiam tanto a ressignificação do mundo social quanto a reorganização de si no aprendizado de outras maneiras de se conceber e vivenciar a diversidade sexual.

Se realmente pudermos admitir que, em face de seus emaranhados narrativos, um texto não precisa ser um manual para se articular uma discussão predefinida, então sua leitura deve ser compreendida como a possibilidade de se articular um ambiente pedagógico no qual múltiplas reflexões podem vir a se desenrolar. Nas narrativas, encontramos as marcas das intenções da autora, bem como o protagonismo das significações de cada leitora, e esses trânsitos evidenciam que um texto nunca é autônomo, mas conjecturado a partir do diálogo com elementos que vêm de fora dele. Conforme Lajolo (2009, p. 108), a perspectiva coletiva das práticas sociais de leitura se compõe por meio de um emaranhado de fios nos quais os textos se tecem e se soltam, “amarrando-se e desamarrando-se uns aos outros". Em meio a essa tessitura social, evidenciam-se os pontos nos quais se arrematam as potências metodológicas das práticas de leitura literária na escola, potências que se constituem pelo cruzamento de interpretações múltiplas não como um pretexto para o debate da sociologia, mas sim como o estabelecimento de um contexto possível de significação.

\section{CONSIDERAÇÕES FINAIS}

O debate sobre gênero e sexualidade nas escolas está sob contínuas vigilâncias, questionamentos e ataques, pois é foco de investidas conservadoras que vêm se legitimando cada vez mais em nosso país. Segundo Biroli (2018), ao serem acusados de parciais, tais eixos curriculares são associados a "ideologias doutrinadoras" que devem ser eliminadas, na medida em que articulam uma "ameaça" aos princípios da então "família tradicional". O ideário de "ameaça” se associa justamente ao intuito desnaturalizador e reflexivo que tais debates articulam enquanto perspectivas sociológicas acerca das relações de poder e dominação inerentes a uma sociedade sexista, racista, classista e heteronormativa (Carniel e Bueno, 2018).

Ativando marcos epistêmicos que influenciam o modo como enxergamos o mundo, e, ainda, como nos enxergamos nele, o debate sobre gênero e sexualidade configura-se no ambiente escolar enquanto um reposicionamento epistemológico que coloca em perspectiva esquemas mentais que nos orientam tanto em nível social quanto em nível individual. Desse modo, as dificuldades que assolam tais reflexões não se conjecturam apenas fora dos "muros da escola", mas também encontram 
percalços por entre as próprias vivências juvenis escolares. Tratar de assuntos que se conectam à esfera da intimidade reverbera como uma experiência "peculiar" para jovens que, muitas vezes, não se sentem à vontade ou não estão dispostas a problematizar noções tão enraizadas - (re)pensar metodologias de ensino, portanto, apresenta-se como um exercício indispensável às práticas de ensino que se proponham significativas tanto dentro quanto fora das salas de aula.

A partir dessas considerações, salientamos o fato de que, enquanto metodologia de ensino e aprendizagem sugerida, a leitura literária vivenciada de forma coletiva favorece o compartilhamento de interpretações, criando um contexto de diálogo reflexivo entre narrativas, interpretações e conceitos sociológicos. Em meio às dinâmicas interpretativas, os textos colocam em perspectiva noções prévias que são reivindicadas no processo de atribuição de sentido às histórias, processo que abre margens ao estabelecimento de uma dinâmica circular, que coloca em trânsito narrativas literárias e narrativas juvenis. Essa circulação de histórias favorece o desenvolvimento de reflexões sociológicas de forma menos impositiva (movimento imprescindível ao debate de temas socialmente considerados "polêmicos", como os que envolvem as relações de gênero e sexualidade na atualidade), possibilitando tanto uma experiência de análise macroestrutural quanto uma reorganização de si a partir de caminhos não exclusivos, unilaterais e engessados.

Desse modo, encontramos reflexões sobre tal atividade social de negociação de sentidos associadas ao conceito de letramento, ao passo em que todo esse emaranhado narrativo está envolto de em usos sociais conectados aos contextos sociais, políticos e culturais mais amplos que perpassam as vivências dessas alunas em diversos níveis. E é justamente nesse aspecto que o debate sociológico permeado por narrativas (literárias e juvenis) pareceu ganhar espaço, em meio às vivências estudantis que protagonizaram tais dinâmicas reflexivas a partir de novos (ou ao menos diferentes) tipos de interesse e engajamento. Como observam Bezerra e Romko (2016,p. 165), pela via dos "vínculos identitários e afetivos" postos em perspectiva por meio do discurso ficcional, abre-se um caminho para o "conhecimento que atribui sentido ao mundo na medida em que informa práticas e que sustenta laços de pertencimento", promovendo oportunidades efetivas para a aprendizagem das relações societárias.

Portanto, argumentamos em favor das potencialidades da mediação literária para a prática pedagógica feminista, prática esta que visa articular um reposicionamento epistemológico quanto às questões que cercam as dinâmicas de gênero e sexualidade por meio de elementos que façam sentido às vivências estudantis. As narrativas literárias entrelaçadas às narrativas estudantis sugerem, assim, um terreno fértil para o desenvolvimento de tais perspectivas - ou, ao menos, indicam caminhos que podem ser mais bem investigados.

\section{REFERÊNCIAS}

AMÉRICO, B.; CARNIEL, F.; TAKAHASHI, A. Gestão pública da educação especial e formalismo nas políticas públicas inclusivas - o caso do Brasil. Ensaio: Avaliação Política Pública Educacional, Rio de Janeiro, v. 22, n. 83, p. 379-410, abr.jun. 2014. Disponível em: https://doi.org/10.1590/s0104-40362014000200006. Acesso em: 14 set. 2021. 
BEZERRA, R.; ROMKO, I. Sociologia e literatura: reflexão e prática sobre o uso da ficção no ensino de sociologia. Revista Urutágua, Maringá, n. 35, p. 163-179, dez./maio 2016. Disponível em: https://doi.org/10.4025/revurut.vi35.37004. Acesso em: 14 set. 2021. BIROLI, F. Reação Conservadora, Democracia e Conhecimento. Revista de Antropologia da USP, SÃO PAULO, V. 61, N. 1, P. 83-94, 2018. Disponível em: https://doi.org/10.11606/2179-0892.ra.2018.145515. Acesso em: 14 set. 2021.

CARNIEL, F. A reviravolta discursiva da Libras na educação superior. Revista Brasileira de Educação, Rio de Janeiro, v. 23, e230027, maio 2018. Disponível em: https://doi.org/10.1590/S1413-24782018230027. Acesso em: 14 set. 2021.

CARNIEL, F.; BUENO, Z. P. O ensino de sociologia e os seus públicos. Educação \& Sociedade, Campinas, v. 39, n. 144, p. 671-685, set. 2018. Disponível em: https://doi. org/10.1590/ES0101-73302018186181. Acesso em: 14 set. 2021.

CARNIEL, F.; RUGGI, L. O. De sociólogo e de louco todo mundo tem um pouco: ou porque a sociologia é a disciplina mais legal da escola. Revista Linhas, Florianópolis, v. 16, n. 30, p. 235-247, abr. 2015. Disponível em: https://doi.org/10.5965/198472381 6302015235. Acesso em: 14 set. 2021.

CARNIEL, F.; RUGGI, L.; RUGGI,J. Gênero e humor nas redes sociais: a campanha contra Dilma Rousseff no Brasil. Opinião Pública, Campinas, v. 24, n. 3, p. 523-546, dez. 2018. Disponível em: https://doi.org/10.1590/1807-01912018243523. Acesso em: 14 set. 2021.

CASTARÈDE, M. La voix et sés sortilèges. Paris: Les Belles Letres, 2000.

COSSON, R. Letramento literário: teoria e prática. São Paulo: Contexto, 2018.

COSSON, R.; SOUZA, R. J. Letramento literário: uma proposta para a sala de aula. Objetos Educacionais UNESP,São Paulo, p.101-107,2011.Disponível em: https://acervodigital.unesp. br/bitstream/123456789/40143/1/01d16t08.pdf. Acesso em: 14 set. 2021.

FLORESTA, N. Liberdade e educação para a mulher brasileira. In: BUENO, A. (org.). Textos sobre história das mulheres. Rio de Janeiro: Ebook, 2016. p. 181-183.

GILMAN, C. O papel de parede amarelo. Rio de Janeiro: José Olympio, 2016. GROSFOGUEL, R. A estrutura do conhecimento nas universidades ocidentalizadas. Racismo/sexismo epistêmico e os quatro genocídios/epistemicídios ao longo do século XVI. Revista Sociedade e Estado, Brasília, v.31, n. 1, p. 25-49, jan./abr. 2016. Disponível em: https://doi.org/10.1590/S0102-69922016000100003. Acesso em: 14 set. 2021.

HIRSCHMAN, S. Gente y cuentos: ¿¿A quién pertenece la literatura? Las comunidades encuentran su voz a través de los cuentos. Buenos Aires: Fondo de Cultura Económica, 2011.

HOOKS, B. Ensinando a transgredir: a educação como prática de liberdade. São Paulo: Martins Fontes, 2013.

LAJOLO,M.O texto não é pretexto. Será que não é mesmo? In:ZILBERMAN, R.; ROSING, T. (org.). Escola e leitura: velha crise, novas alternativas. São Paulo: Global, 2009. p. 99-112.

MACEDO, M. Literacy in elementary school: reading Dom Quixote de la Mancha. Revista Brasileira de Estudos Pedagógicos, Brasília, v. 100, n. 254, p. 39-53, jan./abr. 2019. Disponível em: https://doi.org/10.24109/2176-6681.rbep.100i254.3877. Acesso em: 14 set. 2021. 
PEREIRA, A. "A maior zoeira" na escola: experiências juvenis na periferia de São Paulo. São Paulo: UNIFESP, 2017.

PETIT, M. A arte de ler, ou como resistir à adversidade. São Paulo: Editora 34, 2010. PRESSLEY, M. Reading instruction that works: the case for balanced teaching. New York: Guilford, 2002.

SEOANE, S. Tomar la palabra: apuntes sobre oralidad y lectura. In: CONFERÊNCIA NO CURSO DE POS-GRADUAÇÃO EM LITERATURA INFANTIL E JUVENIL, 2004, Buenos Aires. Anais [...]. Buenos Aires: CePA, 2004.

\section{SOBRE OS AUTORES}

Andressa Fontana Pires é mestre em sociologia pela Universidade Federal do Paraná (UFPR).

E-mail: andressafonti@gmail.com

Fagner Carniel é doutor em sociologia política pela Universidade Federal de Santa Catarina (UFSC). Professor da Universidade Estadual de Maringá (UEM).

E-mail: fagnercarniel@yahoo.com.br

Conflitos de interesse: Os autores declaram que não possuem nenhum interesse comercial ou associativo que represente conflito de interesses em relação ao manuscrito.

Financiamento: Não houve financiamento.

Contribuições dos autores: Investigação, Escrita - Primeira Redação: Pires, A. F. Supervisão, Escrita - Revisão e Edição: Carniel, F.

Recebido em 16 de junho de 2020 Aprovado em 2 de fevereiro de 2021 